\title{
EFFECT OF MANGANESE DURING THE STABILIZATION OF AUSTENITE IN QUENCH AND PARTITIONING (Q\&P) STEELS
}

\author{
${ }^{1}$ Marcel CARPIO, ${ }^{1}$ Jessica MUÑOZ, ${ }^{2}$ Omar GARCÍA, ${ }^{2} J u a n$ Pablo PEDRAZA, \\ 1 José Mara CABRERA
}

\begin{abstract}
${ }^{1}$ Department of Materials Science and Metallurgical Engineering, EEBE, Polytechnic University of Catalonia, Diagonal Besòs Campus, Barcelona, Spain, EU, marcel.francisco.carpio@upc.edu

${ }^{2}$ TERNIUM Mexico, San Nicolas de los Garza, Nuevo Leon, Mexico
\end{abstract}

https://doi.org/10.37904/metal.2019.711

\begin{abstract}
Nowadays, automobile emissions are one of the leading causes of air contamination. In this regard, the weight reduction of the vehicles structures and parts is vital, while the passenger's safety is the first issue. Therefore, high demand for Advanced High Strength Steels (AHSS), is constantly increasing in the automotive industry, which can adequately fulfill both safety and emissions issues through reduction in thickness. A new generation of AHSS covers these demands owing to excellent forming and mechanical properties. Accordingly, Quenching and Partitioning (Q\&P) steels have been developed with a special microstructure composed of an initial fraction of martensite and a slight fraction of stabilized retained austenite. The aim of the present work is to assess the effect of different amounts of manganese in Q\&P steel under various heat treatment cycles relevant to an industrial process. A $0.2 \mathrm{C}-1.5 \mathrm{Si}$ base steel with different amount of $\mathrm{Mn}$, namely 1.5, 3.5 and 5.5 (in wt\%) were selected to promote different amounts of retained austenite after Q\&P process. In order to determine the critical transformation temperatures such as $\mathrm{Ac}_{1}, \mathrm{Ac}_{3}, \mathrm{M}_{\mathrm{s}}$ and $\mathrm{M}_{\mathrm{f}}$, which are needed to design Q\&P thermal cycles, dilatometric experiments were carried out. The results are presented according to the chemical composition, the final microstructure and the hardness obtained in each condition.
\end{abstract}

Keywords: Quenching and Partitioning, high manganese, retained austenite

\section{INTRODUCTION}

The automotive industry seeks to develop new alloys of steel for the manufacture of automotive parts to reduce the weight of the car and improve the safety of passengers. Quench and Partitioning (Q\&P) steels, pertaining to the 3rd generation of High Strength Advanced Steels (AHSS), are candidates to cover these needs due to their good properties of strength and formability [1]. The Q\&P process was first proposed by Speer et al. [2], and consists basically of an interrupted quench treatment to form an adequate fraction of martensite and retained austenite, followed by a carbon partitioning between martensite and austenite to enrich the latter, avoiding the formation of secondary phases, and finishing with a final quenching, so that a final microstructure of tempered martensite, fresh martensite and retained austenite is obtained. The latter provides a transformation-induced plasticity effect (TRIP) which can be of great help in increasing the formability when manufacturing the component and in the absorption of energy during the behavior in service [3]. It has been reported that high fractions of austenite retained in the microstructure improve the total elongation and provide an increase in the hardening by deformation by the TRIP effect [4]. It has also been reported that, in addition to carbon, the diffusion of substitutional elements, such as manganese, can help to stabilize the austenite. By means of controlled additions of $\mathrm{Mn}$, the stabilization of the austenitic phase can be improved and the starting temperature of martensitic transformation (Ms) reduced [5,6]. In the present work, and starting from a basis chemical composition of $0.2 \mathrm{C}-1.5 \mathrm{Si}$ [7], three alloys with different nominal amounts of manganese (1.5, 3.5, $5.5 \mathrm{wt} \%$ ) were designed to analyse the effect of this element on the stability of austenite and other constituents For this purpose, the continuous cooling diagrams of all the steels were determined, as well as the corresponding characteristic transition temperatures, in order to be able to correctly design a Q\&P treatment. 


\section{EXPERIMENTAL PROCEDURE}

\subsection{Material and microstructural characterization}

Table 1 shows the actual chemical composition of the steels selected for this study. These were manufactured in the form of ingots by Vacuum Induction Meting, and subsequently hot rolled to break the dendritic microstructure and allowed to cool in air. Each steels sheets with a thickness of approximately $7 \mathrm{~mm}$ were obtained.

Table 1 Chemical composition of the studied steels

\begin{tabular}{|c|c|c|c|}
\hline \multicolumn{4}{|c|}{ Chemical composition (wt\%) } \\
\hline Steel & C & Mn & Si \\
\hline A & 0.27 & 1.47 & 1.59 \\
\hline B & 0.22 & 3.72 & 1.43 \\
\hline C & 0.25 & 5.67 & 1.33 \\
\hline
\end{tabular}

In order to obtain the critical transformation temperatures $\left(\mathrm{Ac}_{1}, \mathrm{Ac}_{3}\right)$ and the temperatures corresponding to the start and end of the martensitic transformation (Ms, Mf), dilatometry studies were carried out in a DIL 805A unit. To this aim, cylindrical samples with dimensions of $10 \mathrm{~mm}$ in length with a radius of $4 \mathrm{~mm}$ were machined from the steel sheets. Each steel samples were austenitized at a temperature of $1100^{\circ} \mathrm{C}$ at a heating rate of $10^{\circ} \mathrm{C} / \mathrm{s}$ to ensure complete homogenization. Once the selected temperature was reached, direct quenching was applied at a rate of $50{ }^{\circ} \mathrm{C} / \mathrm{s}$ to room temperature to ensure a complete martensitic transformation in all three steels. Next, the continuous cooling transformation CCT diagrams were derived in the same dilatometer, and with specimens of identical dimensions. For these tests, the 3 steels were heated at a rate of $10^{\circ} \mathrm{C} / \mathrm{s}$, until reaching $\mathrm{Ac}_{3}+50{ }^{\circ} \mathrm{C}$, where they were maintained for one minute. Next, the samples were cooled at different rates $\left(100,50,20,10,5,1,0.1^{\circ} \mathrm{C} / \mathrm{s}\right)$ and the transformation temperatures of each phase were determined according to the cooling rate itself.

The specimens obtained from the aforementioned dilatometry tests, such as those of the material in the asreceived state, were prepared adequately for metallographic analysis. For this purpose, the samples of each condition were polished with sandpapers of decreasing granulometry followed by a final polishing in alumina of $1 \mu \mathrm{m}$. Subsequently, they were chemically etched with Nital $2 \%$ to reveal their microstructure and facilitate their analysis. On the other hand, microhardness measurements were made in the centre of each sample and in each condition by means of a matrix of $3 \times 3$ and $1 \mathrm{Kg}$ of load to have an average value of the whole sample.

\section{RESULTS AND DISCUSSION}

The microstructures of the samples in as-received state are shown in Figure 1. In steel A (Figure1a) a microstructure formed by ferrite (lighter phase) and perlite (darker phase) can be observed, while in steels $B$ and $C$ (Figures $\mathbf{1 b}$ and $\mathbf{1 c}$ ) a microstructure formed entirely by martensite can be noticed. These results are consistent with values reported in the literature [8], and indicate the great hardenability that the current steels acquire when the $\mathrm{Mn}$ content is higher than 3.5 (wt\%).

The corresponding hardness results are shown in Table 2, and are consistent with the microstructures observed in Figure 1. However, steels $B$ and $C$ should have given a similar hardness value because they were $100 \%$ martensitic, as it is typically assumed that the value of the hardness of martensite only depends on the $\mathrm{C}$ content. If the content in $\mathrm{C}$ is similar, the hardness should have been similar. However, almost $100 \mathrm{HV}$ of difference is obtained being $\mathrm{C}$ similar in steels $\mathrm{B}$ and $\mathrm{C}$. These results suggest that the $\mathrm{Mn}$ content may also influence the hardness of the martensite. 

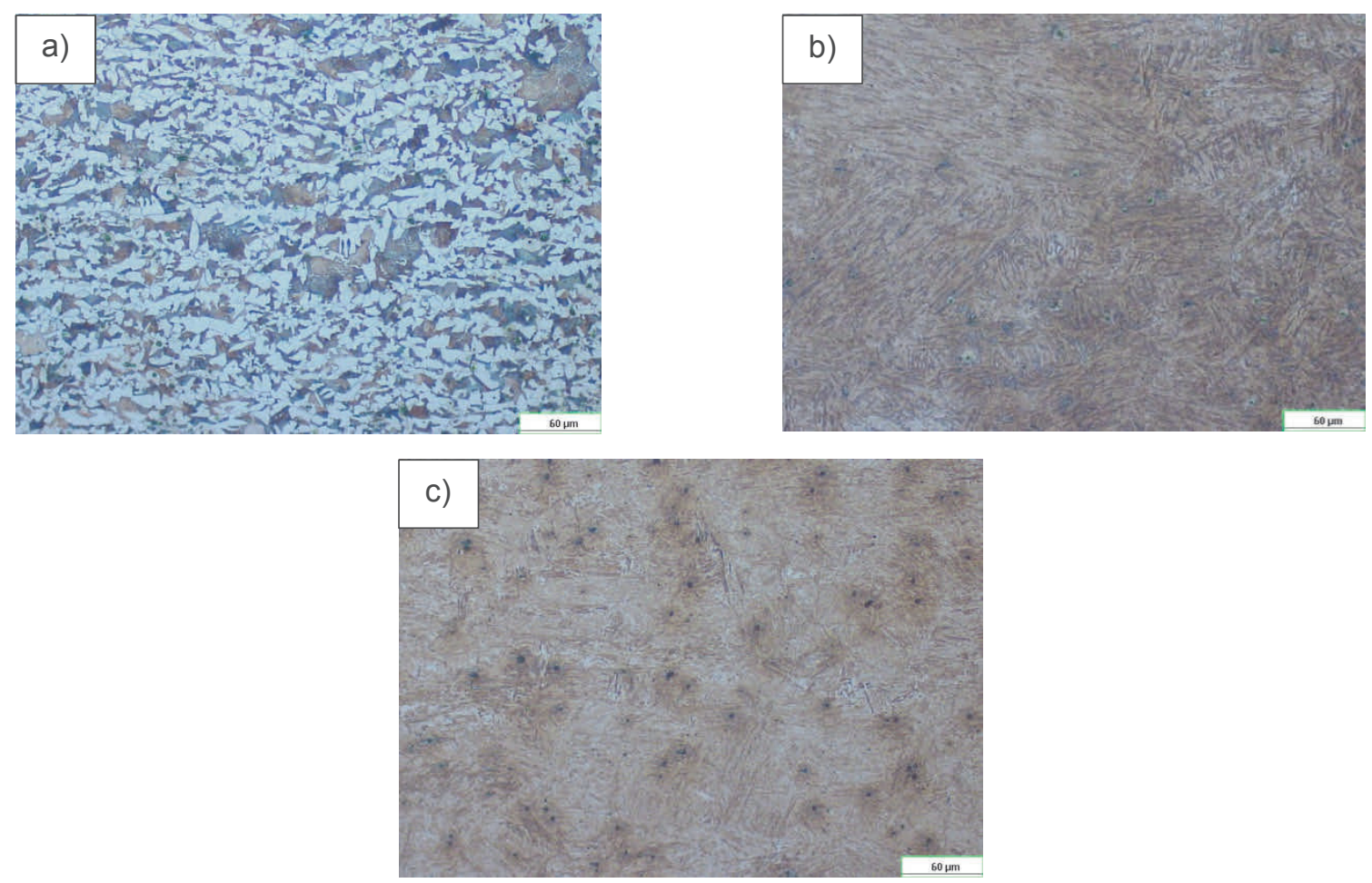

Figure 1 As-received microstructures a) Steel 1, b) Steel 2, c) Steel 3

Table 2 As received hardness of the studied steels

\begin{tabular}{|c|c|}
\hline Steel & Hardness \\
\hline A & $208 \mathrm{HV}$ \\
\hline B & $460 \mathrm{HV}$ \\
\hline C & $535 \mathrm{HV}$ \\
\hline
\end{tabular}

There are several empirical formulas to calculate the transformation temperatures in steel based on the chemical composition. Most of them have been developed based on the analysis of experimental data [9]. For example, Eq. (1) shows an expression to obtain the temperature $\mathrm{Ac}_{3}$, based on the content of $\mathrm{C}, \mathrm{Si}, \mathrm{Mn}, \mathrm{V}$, Mo, Ni and $\mathrm{Cr}$ [10]. Eq. (2) is commonly used to determine the Ms temperature of a steel based on the contents of $\mathrm{C}, \mathrm{Mn}, \mathrm{Si}$ and $\mathrm{Al}[2]$.

$A c_{3}\left({ }^{\circ} \mathrm{C}\right)=902-255 \mathrm{C}+19 \mathrm{Si}-11 \mathrm{Mn}-5 \mathrm{Cr}+13 \mathrm{Mo}-20 \mathrm{Ni}+55 \mathrm{~V}$

$M_{S}\left({ }^{\circ} \mathrm{C}\right)=539-423 \mathrm{C}-30.4 \mathrm{Mn}-7.5 \mathrm{Si}+30 \mathrm{Al}$

Table 3 shows the transformation temperatures of steels $A, B$, and $C$ calculated by the empirical equations Eq. (1) and Eq. (2). The experimental characteristic temperatures $A_{c_{1}}, A_{c_{3}}, M s$ and $M f$ of these steels obtained by means of the dilatometry tests are also shown in Table 3. As expected, it can be observed that as the manganese concentration increases all the critical temperatures of transformation decrease, confirming the stabilizing role of the austenite played by this alloying element. [1,11]. In general, the values predicted by the empirical expression tend to give $\mathrm{Ac}_{3}$ values much lower than the experimental ones. This does not happen with the values of Ms, where the prediction (except in steel $\mathrm{A}$ ) is almost perfect. On the other hand, the interval between the temperatures $\mathrm{Ms}$ and $\mathrm{Mf}$ deserves to be highlighted. This value is very important because between these temperatures the interrupted quenching is produced to obtain the largest possible fraction of retained austenite, and indicates the margin for such quenching. Table 3 illustrates that there is no clear dependence of this interval on the chemical composition, since it does not increase continuously with the Mn 
content. In fact, steel B only has an interval of $115^{\circ} \mathrm{C}$ to be able to interrupt the quench, while it is 155 and $183^{\circ} \mathrm{C}$ for steels $\mathrm{A}$ and $\mathrm{C}$ respectively. It is also worth mentioning the strong dependence of $\mathrm{Mf}$ with the content in Mn. While in steels $\mathrm{A}$ and $\mathrm{B}$ the temperature $\mathrm{Mf}$ is 233 and $206{ }^{\circ} \mathrm{C}$ respectively, it goes down to $67^{\circ} \mathrm{C}$ in steel $\mathrm{C}$. This fact predicts that in the second quenching, with the retained austenite very enriched in carbon, the final temperature $\mathrm{Mf}$ can be well below the ambient temperature.

Table 3 Steel transformation temperatures calculated by empirical equations (1) and (2) and dilatometry

\begin{tabular}{|c|c|c|c|c|c|c|c|}
\hline Steel & $\mathbf{A c _ { 3 } ( 1 )}$ & $\mathbf{M}_{\mathbf{s}}(\mathbf{2})$ & $\mathbf{A \mathbf { c } _ { 1 }}$ & $\mathbf{A \mathbf { c } _ { 3 }}$ & $\mathbf{M}_{\mathbf{s}}$ & $\mathbf{M}_{\mathbf{f}}$ & $\mathbf{M}_{\mathbf{s}}-\mathbf{M}_{\mathbf{f}}$ \\
\hline $\mathrm{A}$ & $847^{\circ} \mathrm{C}$ & $368^{\circ} \mathrm{C}$ & $764^{\circ} \mathrm{C}$ & $897^{\circ} \mathrm{C}$ & $388^{\circ} \mathrm{C}$ & $233^{\circ} \mathrm{C}$ & $155^{\circ} \mathrm{C}$ \\
\hline $\mathrm{B}$ & $832^{\circ} \mathrm{C}$ & $322^{\circ} \mathrm{C}$ & $729^{\circ} \mathrm{C}$ & $869^{\circ} \mathrm{C}$ & $321^{\circ} \mathrm{C}$ & $206^{\circ} \mathrm{C}$ & $115^{\circ} \mathrm{C}$ \\
\hline $\mathrm{C}$ & $801^{\circ} \mathrm{C}$ & $250^{\circ} \mathrm{C}$ & $716^{\circ} \mathrm{C}$ & $821^{\circ} \mathrm{C}$ & $250^{\circ} \mathrm{C}$ & $67{ }^{\circ} \mathrm{C}$ & $183^{\circ} \mathrm{C}$ \\
\hline
\end{tabular}

On the other hand, Figure 2 shows the results obtained from the study of continuous cooling curves (CCT). Figure $2 \mathrm{a}$ shows this diagram for steel $\mathrm{A}$. where one can observe the transformation temperatures and the different phases that can be obtained with the different cooling rates, as well as the hardness reached in each condition. The diagram shows that for steel $A$ at least a cooling rate of $50{ }^{\circ} \mathrm{C} / \mathrm{s}$ is needed to achieve a completely martensitic microstructure, while at lower rates undesirable phases are obtained. Figure $\mathbf{2 b}$ corresponds to a better detail of the hardness reached in each condition for this steel. An increase in hardness can be observed as the cooling rate is increased to a hardness of $498 \mathrm{HV}$ at a cooling rate of $100{ }^{\circ} \mathrm{C} / \mathrm{s}$, as a result of a completely martensitic structure. Note that the saturation of the hardness occurs at the moment that the microstructure is fully martensitic.

The results obtained for steel $\mathrm{B}$ are shown in Figure 3. The CCT diagram is illustrated in Figure $\mathbf{3 a}$, and it can be seen that the martensitic phase prevails at most cooling rates, except at $0.1{ }^{\circ} \mathrm{C} / \mathrm{s}$ which presents an additional phase in the martensitic matrix. That is, the microstructure is totally martensitic when cooling rate is faster than $1^{\circ} \mathrm{C} / \mathrm{s}$. The hardness values reached in this steel are shown in Figure $\mathbf{3 b}$, where it can be seen that a hardness of $429 \mathrm{HV}$ was obtained at a rate of $0.1^{\circ} \mathrm{C} / \mathrm{s}$, while increasing the rate can promote a hardness close to $525 \mathrm{HV}$ which saturates practically from the slowest rates, confirming that at almost all cooling rates the microstructure is totally martensitic. Compared to steel $\mathrm{A}$, the temperature $\mathrm{Ms}$ is reduced, while the curves of transformation of secondary phases in steel B disappear from the diagram.

Figure 4 shows the results corresponding to steel C. The CCT diagram shows that it is self-quenching steel. At any cooling rate of those tested the microstructure is totally martensitic as shown in Figure $\mathbf{4 a}$. Rates as slow as $0.1^{\circ} \mathrm{C} / \mathrm{s}$ promote completely martensitic structures, which would facilitate the industrial implementation of this process. On the other hand, the hardness reached in this steel is above $500 \mathrm{HV}$ and increase somehow as the cooling rate increases to reach $583 \mathrm{HV}$.
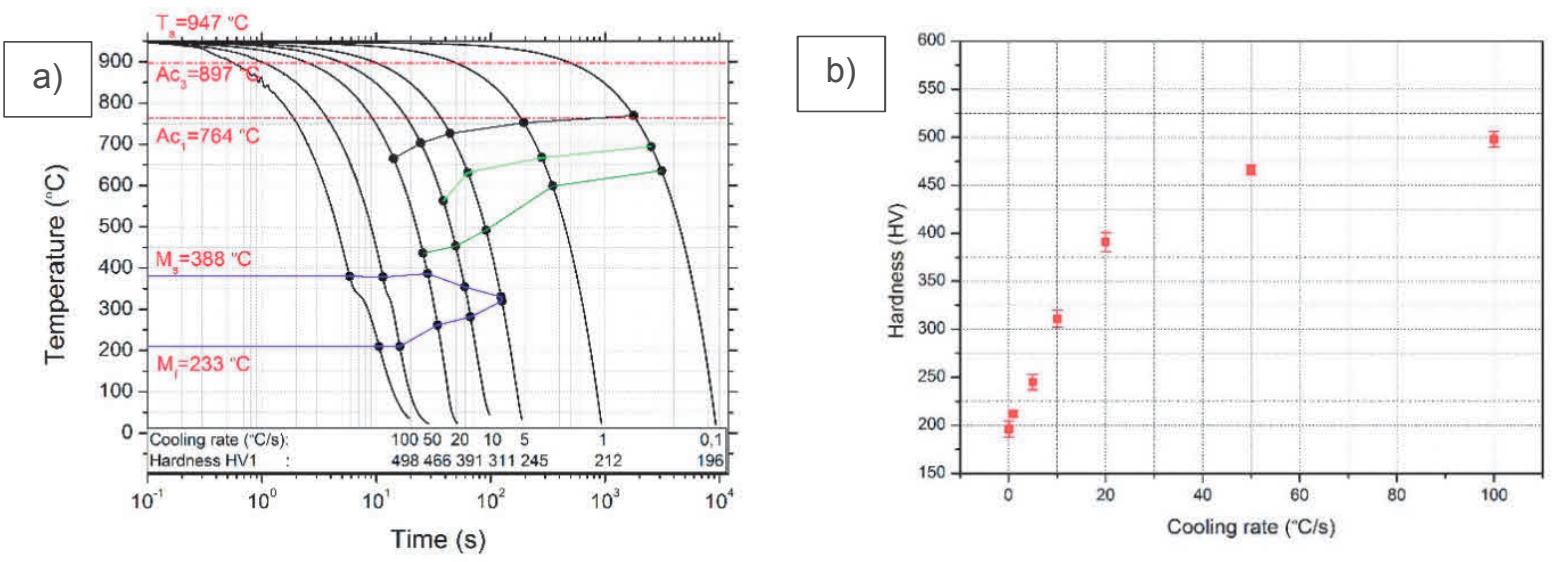

Figure 2 Steel A. a) CCT diagram, b) Hardness vs cooling rate 

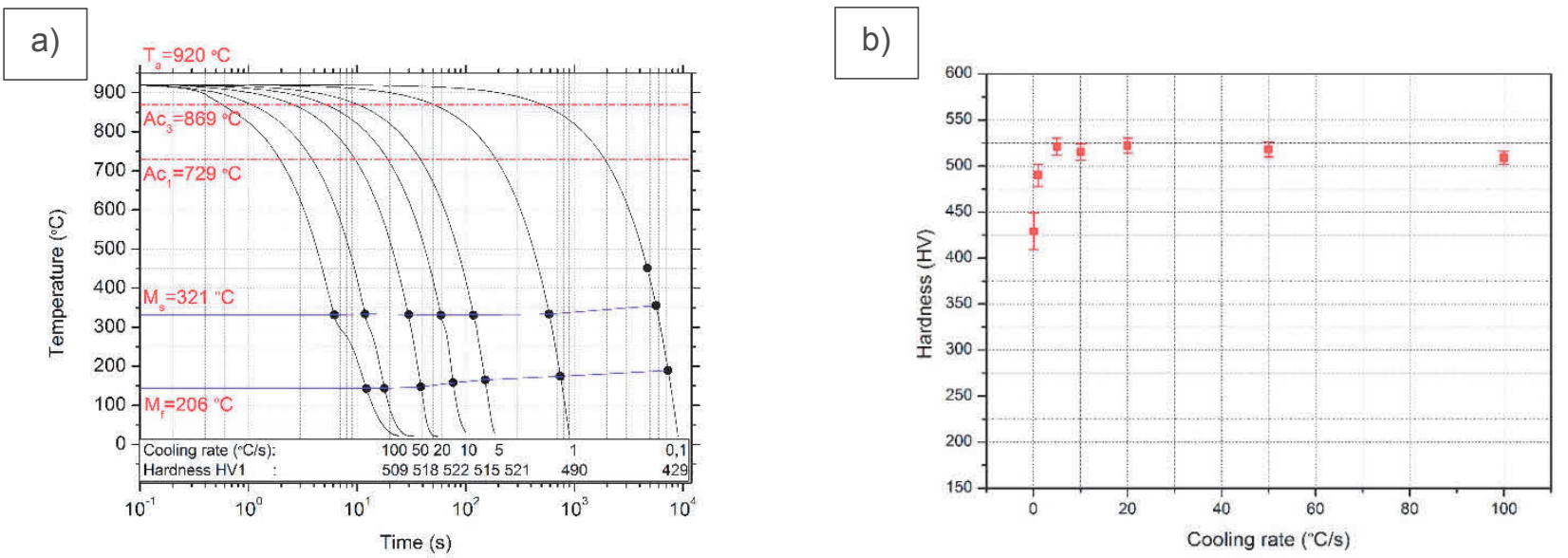

Figure 3 Steel B. a) CCT diagram, b) Hardness vs cooling rate
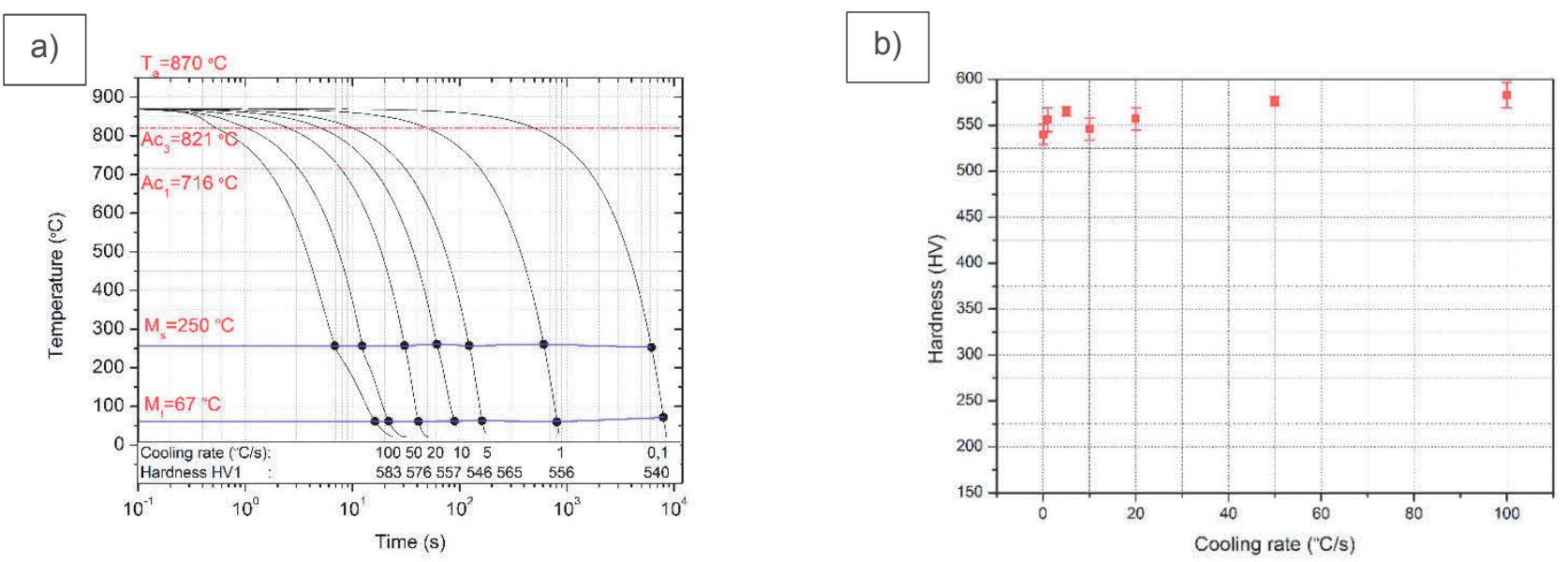

Figure 4 Steel C. a) CCT diagram, b) Hardness vs cooling rate

By comparison of the CCT diagrams, steels $B$ and $C$ only differ practically in the value of Ms and in the obtained hardness, being higher in steel $C$ than in steel $B$. Differences in hardness cannot be explained only by the small difference in $\mathrm{C}$, and can only be attributed to the higher content in $\mathrm{Mn}$. This is also consistent with the hardness values of steel $A$ when the structure is totally martensitic. The comparison between steel $A$ and steels $\mathrm{B}$ and $\mathrm{C}$ shows that increasing the Mn content from $1.5(\mathrm{wt} \%)$ to $3.5(\mathrm{wt} \%)$ makes the steel practically selfquenchable.

\section{CONCLUSION}

It can be seen that with the increase of manganese, the critical temperatures $A c_{1}$ and $A c_{3}$ are reduced, promoting the stability of the austenite, while the temperatures Ms and Mf are also significantly reduced by the addition of this element, especially in the steel $\mathrm{C}$. According to the obtained results, it can be determined that high concentrations of manganese (> 3.5 (wt $\%)$ in this type of alloys would favor the formation of martensite at cooling rates as slow as $1^{\circ} \mathrm{C} / \mathrm{s}$, which would facilitate the implementation of industrial Q\&P process. The hardness results indicate that the hardness of the martensite is basically independent of the cooling rate, but not on the Mn content. Therefore, the $\mathrm{C}$ content is not the only dominant element in the hardness value of the martensite. 


\section{ACKNOWLEDGEMENTS}

The authors would like to thank CONACYT (Mexico) for the support granted to this project.

\section{REFERENCES}

[1] FONSTEIN, N. Advanced High Strength Sheet Steels. $1^{\text {st }}$ ed. New York: Springer International Publishing, 2015. p. 369.

[2] SPEER, J. G., STREICHER, A. M., MATLOCK, D. K., RIZZO, F., \& KRAUSS, G..Quenching and partitioning: a fundamentally new process to create high strength trip sheet microstructures. In Symposium on the Thermodynamics, Kinetics, Characterization and Modeling of: Austenite Formation and Decomposition, E.B. Damm, M. Merwin, editors, Warrendale, PA: TMS/ISS; 2003, pp. 505-522.

[3] SPEER, J. G., ASSUNÇÃO, F. C. R., MATLOCK, D. K. and EDMONDS, D. V. (2005). The quenching and partitioning process: background and recent progress. Materials Research. 2005. vol. 8, no. 4, pp. 417-423.

[4] DE KNIJF, D., PETROV, R., FÖJER, C. and KESTENS, L. A. (2014). Effect of fresh martensite on the stability of retained austenite in quenching and partitioning steel. Materials Science and Engineering: 2005. Vol. A 615, pp. 107-115.

[5] LEE, S., LEE, S. J. and DE COOMAN, B. C. Austenite stability of ultrafine-grained transformation-induced plasticity steel with Mn partitioning. Scripta Materialia. 2011. vol. 65, no. 3, pp. 225-228.

[6] HOU, Z. R., ZHAO, X. M., ZHANG, W., LIU, H. L. and YI, H. L. (2018). A medium manganese steel designed for water quenching and partitioning. Materials Science and Technology. 2018. vol. 34, no. 10, pp. 1168-1175.

[7] Wang, L. and Speer, J. G. Quenching and partitioning steel heat treatment. Metallography, Microstructure, and Analysis. 2013. vol. 2, no. 4, pp. 268-281.

[8] DE MOOR, E., MATLOCK, D. K., SPEER, J. G., \& MERWIN, M. J. (2011). Austenite stabilization through manganese enrichment. Scripta Materialia. 2011. vol. 64. No. 2, pp. 185-188.

[9] KRAUSS, G. Steels: processing, structure, and performance. 2nd ed. Materials Park, OH, ASM International, 2015. p. 31.

[10] KIM, H., INOUE, J., OKADA, M. and NAGATA, K. Prediction of Ac3 and Martensite Start Temperatures by a Data-driven Model Selection Approach. ISIJ International. 2017. vol. 57, no. 12, pp. 2229-2236.

[11] LEE, S. and DE COOMAN, B. C. Tensile behavior of intercritically annealed 10 pct Mn multi-phase steel. Metallurgical and Materials Transactions A. 2014. vol. 45, no. 2, pp. 709-716. 